\title{
Evaluation of Ki-67 in Breast Cancer
}

\author{
Arumugam Velappan ${ }^{1}$, Deepa Shunmugam ${ }^{2}$ \\ ${ }^{I}$ (Department Of Medical Oncology, Tirunelveli Medical College / TN Dr MGR Medical University, India) \\ ${ }_{2}^{2}$ (Department Of Surgical Oncology, Tirunelveli Medical College/ TN Dr MGR Medical University, India)
}

\begin{abstract}
Breast cancer is now the common cause of cancer-related death among women. Proliferation markers in breast cancer seem to be a prognostic factor. Immunohistochemistry of the nuclear antigen Ki-67 is the most common proliferation marker used in studies by the assessment of the percentage of cells staining positive for Ki-67. This study analyzed the association between Ki-67 index and clinical parameters, histopathological parameters and intrinsic subtypes of breast cancer. A higher Ki-67 index correlated significantly with young age, larger tumors, and positive lymph nodes.
\end{abstract}

Keywords: Breast Carcinoma, Immunohistochemistry, $K i-67$ index

\section{Introduction}

Breast cancer is now the common cause of cancer-related death among women ${ }^{[1]}$. The 5 year survival rate of breast cancer is up to $81 \%$ which is good when compared to cancer in other sites ${ }^{[2]}$. Tissue markers that have prognostic value include hormone receptors, HER-2 over expression and Ki-67 index. Uncontrolled proliferation is a hallmark of cancer ${ }^{[3]}$. Proliferation markers in breast cancer seem to be a prognostic factor ${ }^{[4]}$. The various types of proliferation markers are mitotic count, S-phase fraction as measured by flow cytometry and immunohistochemistry using monoclonal antibodies to antigens found in dividing cells.

Immunohistochemistry of the nuclear antigen Ki-67 is the most common proliferation marker used in studies by the assessment of the percentage of cells staining positive for $\mathrm{Ki}-67^{[5]}$. There are many potential uses for Ki-67 assessment. These include estimation of residual risk in patients on neoadjuvant chemotherapy, prognosis of breast cancer, prediction of response or resistance to chemotherapy or endocrine therapy and as a bio-marker of treatment efficacy, mainly to neo-adjuvant endocrine therapy.

As per the results of two large meta-analyses Ki-67 is an independent prognostic factor in early breast cancer ${ }^{[6,7]}$. One meta analysis which included 46 studies and 12000 patients concluded that high Ki-67 levels were associated with a high rate of relapse and poor overall survival ${ }^{[6]}$. The use of Ki-67 proliferation index as a prognostic factor in the clinical setting is controversial. This is because of inconsistency in reporting of the Ki67 index even in standard labs in the world ${ }^{[8]}$. Although a report suggests that consistency in reporting is achieved by systematic training ${ }^{[9]}$, ASCO tumor panel has recommended not to use proliferation markers to assess prognosis ${ }^{[10]}$. The International IMPAKT working group is in concordance with ASCO guidelines ${ }^{[11]}$.

\section{Objective}

2.1 To evaluate use of Ki-67 as a prognostic marker in breast cancer

2.2 To analyze the association between Ki-67 index and clinical parameters, histo-pathological parameters and intrinsic subtypes of breast cancer.

\section{Materials And Methods}

This prospective study was conducted at the Department of medical oncology, Regional Cancer Centre Tirunelveli Medical College Hospital for a period of sixteen months from November 2015 to February 2017. About 128 breast cancer patients of all stages who received no previous treatment for any malignancy were included in this study. Case selection was done during the first six month period (November 2015 to April 2016) and they were followed up till February 2017 (Minimum of 10 months to a Maximum of 15 months). Institutional Ethical Committee approval was obtained prior to the start of the study.

The Ki-67 index was measured in all 128 patients along with ER, PR and HER2. Immunohistochemical staining was done and the proportion of the malignant cells staining positive for the nuclear antigen Ki-67 was evaluated in a quantitative and visual way using light microscopes. Ki-67 values were acquired as the percentage of positively marking malignant cells using the anti-human Ki-67 monoclonal antibody MIB1 which is one of the most commonly used antibodies and considered as the "gold standard". The $\mathrm{Ki}-67$ percentage score is defined as the percentage of positively stained tumor cells among the total number of malignant cells assessed. Scoring was done in the whole tumor section. 


\section{Analysis}

Continuous data were expressed as mean \pm standard deviation(SD) and categorical data as frequency counts (percentages). Baseline characteristics of patients were compared among Ki-67 values by analysis of independence and trend for continuous variables and categorical variables, done by Chi square test and Fischer exact test. Ki-67 mean values were compared for each categorical baseline variable. Univariable analyses by the use of the Chi square test were performed to assess the influence of Ki-67 and of established clinical and histopathological parameters. According to the multivariate analysis and due to the non-normal distribution characterized by a few Ki-67 values with a very high frequency count, the Ki-67 values were categories < 20\%, $21-25 \%, 26-30 \%,>30 \%$ for histopathological analyses. Since no imputation methods for missing values were used, the multivariable model contains only patients with full data sets according to the predictive variables. A two-sided $\mathrm{P}$ value of less than 0.05 was considered to indicate the statistical significance. Hazards ratios (HR) and corresponding $95 \%$ confidence intervals (CI) were calculated and considered as statistically significant if CI excluded 1.0. All analyses were performed using Graphpad Instat Version 3.1 and IBM SPSS Statistics V22.0.0.

\section{Results}

The base line characteristics of 128 patients are shown in table 1.

Table 1:

\begin{tabular}{|c|c|c|c|c|}
\hline S No & Characters & Sub-Characters & n (128) & Percentage \\
\hline \multirow[b]{2}{*}{1} & \multirow[b]{2}{*}{ Age } & Mean \pm SD & $48.21 \pm 13.2$ & \\
\hline & & Range & $27-84$ & \\
\hline 2 & BMI & & 26.33 & \\
\hline \multirow{2}{*}{3} & \multirow{2}{*}{ Menopausal Status } & Pre & 68 & 53.1 \\
\hline & & Post & 60 & 46.9 \\
\hline \multirow{4}{*}{4} & \multirow{4}{*}{ Clinical ' $T$ ' Stage } & 1 & 2 & 1.6 \\
\hline & & 2 & 52 & 40.6 \\
\hline & & 3 & 51 & 39.8 \\
\hline & & 4 & 23 & 18 \\
\hline \multirow{4}{*}{5} & \multirow{4}{*}{ Clinical Nodal status } & 0 & 31 & 24.2 \\
\hline & & 1 & 88 & 68.8 \\
\hline & & 2 & 2 & 1.6 \\
\hline & & 3 & 7 & 5.4 \\
\hline \multirow{2}{*}{6} & \multirow{2}{*}{ Metastatic } & Yes & 11 & 8.5 \\
\hline & & No & 117 & 91.5 \\
\hline \multirow{3}{*}{7} & \multirow{3}{*}{ Breast } & Right & 43 & 33.6 \\
\hline & & Left & 84 & 65.6 \\
\hline & & $\mathrm{B} / \mathrm{L}$ & 1 & 0.8 \\
\hline \multirow{2}{*}{8} & \multirow{2}{*}{ Histology } & Ductal & 116 & 90.6 \\
\hline & & Others & 12 & 9.4 \\
\hline \multirow{3}{*}{9} & \multirow{3}{*}{ Grade } & 1 & 17 & 13.3 \\
\hline & & 2 & 60 & 46.9 \\
\hline & & 3 & 51 & 39.8 \\
\hline \multirow{3}{*}{10} & \multirow{3}{*}{ Size } & $\leq 2 \mathrm{~cm} \quad \mathrm{pT} 1$ & 6 & 4.7 \\
\hline & & $2-5 \mathrm{~cm} \quad \mathrm{pT} 2$ & 76 & 59.4 \\
\hline & & $>5 \mathrm{~cm} \quad \mathrm{pT} 3$ & 46 & 35.9 \\
\hline \multirow{4}{*}{11} & \multirow{4}{*}{ Pathological Node } & 0 & 40 & 31.3 \\
\hline & & 1 & 49 & 38.2 \\
\hline & & 2 & 26 & 20.3 \\
\hline & & 3 & 13 & 10.2 \\
\hline \multirow{2}{*}{12} & \multirow{2}{*}{ LVI } & Yes & 91 & 71.1 \\
\hline & & No & 37 & 28.9 \\
\hline \multirow{2}{*}{13} & \multirow{2}{*}{ ER status } & Positive & 45 & 35.2 \\
\hline & & Negative & 83 & 64.8 \\
\hline \multirow{2}{*}{14} & \multirow{2}{*}{ PR status } & Positive & 34 & 26.6 \\
\hline & & Negative & 94 & 73.4 \\
\hline \multirow{3}{*}{15} & & $3+$ Positive & 36 & 28.1 \\
\hline & HER 2 neu status & $2+$ Equiv. & 10 & 7.8 \\
\hline & & $1+$ Negative & 82 & 64.1 \\
\hline
\end{tabular}




\begin{tabular}{|c|c|c|c|c|}
\multirow{3}{*}{16} & \multirow{4}{*}{ Chemotherapy } & NAC & 20 & 15.6 \\
\cline { 3 - 4 } & & Adjuvant & 97 & 75.8 \\
\cline { 3 - 4 } & \multirow{2}{*}{ Post op RT } & Palliative & 11 & 8.6 \\
\hline \multirow{2}{*}{17} & Yes & 81 & 63.3 \\
\hline \multirow{3}{*}{18} & \multirow{3}{*}{ Receptor status } & No & 47 & 36.7 \\
\cline { 3 - 5 } & & ER + PR + & 31 & 24.2 \\
\cline { 3 - 5 } & & ER + PR - & 14 & 10.9 \\
\cline { 3 - 5 } & & ER - PR + & 3 & 2.4 \\
\cline { 3 - 5 } & & ER - PR - & 80 & 62.5 \\
\hline
\end{tabular}

In this study, the distribution of patients in different pathologies and the correlation of Ki-67 across different pathologies were analyzed. A total of 128 patients were included in this study. Among them 12 patients were excluded from analyzing histopathological intrinsic subtypes because of equivocal expression of HER 2 status (HER $2-2+$ ) in 9 patients and 3 patients not fitting into any intrinsic subtypes (they have ER - PR + HER2 -). For all the statistical analysis only 116 patients who fit into the standard intrinsic subtypes were included.

Table 2: Patient characteristics and quartile distribution of Ki-67

\begin{tabular}{|c|c|c|c|c|c|c|c|}
\hline Characters & $\begin{array}{c}\text { Sub } \\
\text { characters }\end{array}$ & $\begin{array}{c}\text { Ki-67[\%] } \\
1^{\text {st } q u a r t i l e} \\
<20 \%\end{array}$ & $\begin{array}{c}\text { Ki-67[\%] } \\
2^{\text {nd }} \text { quartile } \\
20-25 \%\end{array}$ & $\begin{array}{c}\text { Ki-67[\%] } \\
3^{\text {rd quartile }} \\
26-30 \%\end{array}$ & $\begin{array}{c}\text { Ki67[\%] } \\
4^{\text {th }} \text { quartile } \\
>30 \%\end{array}$ & $\begin{array}{l}\text { Total } \\
\mathbf{n}[\%]\end{array}$ & $\begin{array}{c}\text { P' } \\
\text { value }\end{array}$ \\
\hline \multirow[t]{2}{*}{ Age } & Mean & 53.7 & 45.2 & 43 & 38.2 & 48.21 & \\
\hline & Range & $35-84$ & $28-65$ & $28-67$ & $27-50$ & $27-84$ & \\
\hline BMI & & 25.11 & 25.35 & 24.75 & 28.3 & 25.4 & \\
\hline \multirow{2}{*}{$\begin{array}{l}\text { Menstrual } \\
\text { Status }\end{array}$} & Pre & $14(26.9 \%)$ & $27(64.3 \%)$ & $11(84.6 \%)$ & $9(100 \%)$ & $61(52.6 \%)$ & $<0.0001$ \\
\hline & Post & $38(73.1 \%)$ & $15(35.7 \%)$ & $2(15.4 \%)$ & $0(0 \%)$ & $55(47.4 \%)$ & \\
\hline \multirow[t]{3}{*}{ Size } & pT1 & $3(5.8 \%)$ & $3(7.1 \%)$ & $0(0 \%)$ & $0(0 \%)$ & $6(5.2 \%)$ & $<0.0001$ \\
\hline & pT2 & $34(65.4 \%)$ & $21(50.0 \%)$ & $6(42.6 \%)$ & $5(55.6 \%)$ & $66(56.9 \%)$ & \\
\hline & pT3 & $15(28.8 \%)$ & $18(42.9 \%)$ & $7(53.8 \%)$ & $4(44.4 \%)$ & $44(37.9 \%)$ & \\
\hline \multirow{4}{*}{$\begin{array}{c}\text { Pathological } \\
\text { Node }\end{array}$} & 0 & $20(38.5 \%)$ & $12(28.6 \%)$ & $4(30.8 \%)$ & $1(11.2 \%)$ & $37(31.9 \%)$ & $<0.0001$ \\
\hline & 1 & $22(42.3 \%)$ & $15(35.7 \%)$ & $4(30.8 \%)$ & $2(22.2 \%)$ & $43(37.1 \%)$ & \\
\hline & 2 & $7(13.4 \%)$ & $11(26.2 \%)$ & $2(15.4 \%)$ & $4(44.4 \%)$ & $24(20.7 \%)$ & \\
\hline & 3 & $3(5.8 \%)$ & $4(9.5 \%)$ & $3(23.0 \%)$ & $2(22.2 \%)$ & $1210.3 \%)$ & \\
\hline \multirow[t]{2}{*}{ Histology } & Ductal & $46(88.5 \%)$ & $40(95.2 \%)$ & $11(84.6 \%)$ & $9(100 \%)$ & $106(91.4 \%)$ & 0.0004 \\
\hline & Others & $6(11.5 \%)$ & $2(4.8 \%)$ & $2(15.4 \%)$ & $0(0 \%)$ & $10(8.6 \%)$ & $<0.0001$ \\
\hline \multirow[t]{3}{*}{ Grade } & 4 & $12(23.1 \%)$ & $2(4.8 \%)$ & $0(0 \%)$ & $1(11.2 \%)$ & $15(12.9 \%)$ & \\
\hline & 2 & $26(50.0 \%)$ & $23(54.8 \%)$ & $4(30.8 \%)$ & $0(0 \%)$ & $53(45.7 \%)$ & \\
\hline & 3 & $14(26.9 \%)$ & $17(40.5 \%)$ & $9(69.2 \%)$ & $8(88.8 \%)$ & $48(41.7 \%)$ & \\
\hline \multirow[t]{2}{*}{ LVI } & Yes & $34(65.4 \%)$ & $31(73.8 \%)$ & $9(69.2 \%)$ & $9(100 \%)$ & $83(71.5 \%)$ & $<0.0001$ \\
\hline & No & $18(34.6 \%)$ & $11(26.2 \%)$ & $4(30.8 \%)$ & $0(0 \%)$ & $33(28.5 \%)$ & \\
\hline \multirow[t]{2}{*}{ ER Status } & $\mathrm{P}$ & $23(44.2 \%)$ & $13(31.0 \%)$ & $3(23.0 \%)$ & $2(22.2 \%)$ & $41(35.3 \%)$ & 0.002 \\
\hline & $\mathrm{N}$ & $29(55.8 \%)$ & $29(69.0 \%)$ & $10(77.0 \%)$ & $7(77.8 \%)$ & $75(64.7 \%)$ & \\
\hline \multirow[t]{2}{*}{ PR Status } & $\mathrm{P}$ & $19(36.5 \%)$ & $4(9.5 \%)$ & $1(7.6 \%)$ & $2(22.2 \%)$ & $26(22.4 \%)$ & $<0.0001$ \\
\hline & $\mathrm{N}$ & $33(63.5 \%)$ & $38(90.5 \%)$ & $12(92.4 \%)$ & $7(77.8 \%)$ & $90(77.6 \%)$ & \\
\hline \multirow{2}{*}{$\begin{array}{l}\text { HER-2 neu } \\
\text { status }\end{array}$} & $\mathrm{P}$ & $15(28.8 \%)$ & $12(28.6 \%)$ & $6(46.2 \%)$ & $3(33.3 \%)$ & $36(31.0 \%)$ & 0.0239 \\
\hline & $\mathrm{N}$ & $37(71.2 \%)$ & $30(71.4 \%)$ & $7(53.8 \%)$ & $6(66.7 \%)$ & $80(69.0 \%)$ & \\
\hline \multirow{3}{*}{$\begin{array}{l}\text { Receptor } \\
\text { status }\end{array}$} & ER+PR+ & $20(38.5 \%)$ & $6(14.3 \%)$ & $1(7.6 \%)$ & $2(22.0 \%)$ & $29(25.0 \%)$ & $<0.0001$ \\
\hline & ER+PR- & $3(5.8 \%)$ & $7(16.7 \%)$ & $2(15.4 \%)$ & $0(0 \%)$ & $12(10.3 \%)$ & \\
\hline & ER- PR- & $29(55.8 \%)$ & $29(69.0 \%)$ & $10(77.0 \%)$ & $7(77.8 \%)$ & $75(64.7 \%)$ & \\
\hline \multirow[t]{5}{*}{$\begin{array}{l}\text { Histological } \\
\text { Subtypes }\end{array}$} & $\begin{array}{c}\text { Luminal } \\
A^{\prime}\end{array}$ & $15(28.8 \%)$ & $4(9.5 \%)$ & $0(0 \%)$ & $0(0 \%)$ & $19(16.4 \%)$ & $<0.0001$ \\
\hline & $\begin{array}{l}\text { Luminal B } \\
\text { Her 2- }\end{array}$ & $1(1.9 \%)$ & $5(11.9 \%)$ & $2(15.4 \%)$ & $0(0 \%)$ & $8(6.9 \%)$ & \\
\hline & $\begin{array}{c}\text { Luminal B } \\
\text { Her } 2+\end{array}$ & $7(13.5 \%)$ & $4(9.5 \%)$ & $1(7.6 \%)$ & $2(22.2 \%)$ & $14(12.1 \%)$ & \\
\hline & $\begin{array}{c}\text { HER } 2 \\
\text { Enriched }\end{array}$ & $8(15.4 \%)$ & $8(19.1 \%)$ & $5(38.5 \%)$ & $1(11.2 \%)$ & $22(19.0 \%)$ & \\
\hline & Basal like & $21(40.4 \%)$ & $21(50.0 \%)$ & $5(38.5 \%)$ & $6(66.7 \%)$ & $53(45.6 \%)$ & \\
\hline
\end{tabular}

The use of quartiles in table $2(<20 \%, 20-25 \%, 26-30 \%,>30 \%)$ was based on the St Gallen's recommendation 2013 to set a cut off been minor / major 20\%. The mean age is inversely proportional to the Ki-67 index i.e, as the mean age value increases the Ki-67 index decreases. Premenopausal patients were prone to have a higher Ki-67 index, while postmenopausal patients were prone to have a lower Ki-67 index. Majority of patients in this study had pathological T2 and T3 tumors. 59.4\% had pT2 and 35.9\% had pT3 tumors. Concerning the nodal status it was shown that a higher nodal status was associated with higher Ki-67 index. The predominant histology was infiltrating ductal carcinoma (not otherwise specified) which was seen in 
117 patients $(91.4 \%)$ and other histological types were seen in 11 patients $(8.6 \%)$. The grade of the tumor was calculated according to the Scarf-Bloom-Richardson score. The clearest association between Ki-67 index and histopathological parameters was seen in relation to grading. In low grade tumors (G1), the percentage of high Ki-67 index was low. Conversely high grade tumors were associated with high Ki-67 quartiles. Only $29 \%$ of G3 tumors were found in $1^{\text {st }}$ quartile in contrast to $71 \%$ in other quartiles.

Tumors with lymphovascular invasion were inclined to have higher proliferation similar to nodal status. In this study population, forty five patients (35\%) had ER positive status and eighty three patients (65\%) had ER negativity. ER positive tumors were associated with a low Ki-67 index. Sixty percentages of ER positive patients were in the first quartile. And only four percentages of ER positive patients were in fourth quartile. Regarding the PR receptor status, the effect of Ki-67 is almost the same as that of ER receptor status. In terms of HER 2 neu, high Ki-67 index was found in tumors with HER 2 neu over expression.

In this study population, intrinsic subtypes were analyzed. Nineteen patients had Luminal 'A' features (16\%), nine patients had Luminal 'B' Her 2 neu negative ( $8 \%$ ) features, fourteen patients had Luminal 'B' Her 2 neu positive (12\%) features, twenty three patients had HER 2 enriched (19\%) features and fifty one patients had Basal-like (44\%)features (Triple Negative).

\begin{tabular}{|l|c|c|}
\hline \multicolumn{3}{|c|}{ Table 3: Histological sub-types } \\
\hline & $\mathrm{n}[116]$ & $\%$ \\
\hline Luminal 'A' & 19 & 16.4 \\
\hline Luminal 'B' H - & 9 & 7.8 \\
\hline Luminal 'B' H + & 14 & 12.1 \\
\hline HER 2 enriched & 23 & 19.7 \\
\hline Triple Negative & 51 & 44 \\
\hline
\end{tabular}

Among intrinsic subtypes, Luminal 'A' tumors had a low Ki-67 index. Sixty percentage of HER 2 enriched tumors and sixty one percentage of triple negative (basal-like) tumors had a high Ki-67 index ( $\geq 20 \%)$.

\section{Discussion}

Ki-67 was first identified as a nuclear histone protein in 1991 by Gerdes et al. The Ki-67 index is determined in a large proportion of tumors from patients with breast cancer. This study demonstrated that the Ki-67 showed an association with the common histo-pathologic parameters. The effect was clearly seen in the association between Ki-67 and grading. This result reinforces the assumption of a similar behavior of these two parameters, both of which are associated with proliferation. Similarly higher tumor stages and higher nodal status were associated with higher Ki-67 values.

The P-values of all categories in the fourth quartile (Ki-67: 20-25, 26-30 and >30\%) were statistically significant, compared to the first category [Ki-67 $<20 \%$ (median)] which raises the question of an optimal Ki67 cut-off point. This should be a subject of further research. Even though the gene expression profiling is already commercially available to analyze tumor characteristics, currently this method is not likely to be widely adopted in clinical routine work because of high cost and lack of evidence from prospective trials. Previous studies were able to demonstrate that a prognostic model, the IHC 4 score, using ER, PR, HER2, and Ki-67 provides similar prognostic information to that in the 21-gene Genomic Health recurrence score ${ }^{12}$.

Currently, neither the St Gallen nor the ASCO recommendations has introduced breast Cancer Ki-67 as a routine parameter.

In contrast to Ki-67, histological grading has been one of the most commonly used parameters for therapy decision-making for a long time. Grading describes differentiation as well as proliferation in various tumors. The most relevant problem using this factor is reproducibility among different institutions ${ }^{13}$. Elston and Ellis therefore modified the Bloom and Richardson grading system and designed the Nottingham combined histologic grade ${ }^{14}$. Their classification system was an important landmark in terms of achieving reproducibility of grading assessments ${ }^{15}$. Among classical histopathological parameters, grading was strongly correlated to Ki67 - index. This correlation was proven in various former studies ${ }^{16-20}$. These findings are in accordance with our results.

A further powerful correlation was noted in steroid receptor status and Ki-67 corresponding with previous studies. ER status has been largely identified as being inversely correlated with Ki-67, with the higher rates of ER positivity shown in the lowest proliferating tumors ${ }^{21}$. Moreover, it could be demonstrated that high levels of Ki-67 are associated with HER2/-neu positivity according to former studies.

Viale et al. ${ }^{22}$ concluded that higher values of Ki-67-labeling index were associated with adverse prognostic factors. In their univariate analyses, high $(>11 \%)$ Ki-67-labeling index was associated with larger tumors, higher tumor grade, peritumoral vascular invasion, and HER-2 positivity $(\mathrm{P}<0.01)$. Vascular and lymphatic invasion were also associated with higher Ki-67 values as previously described by Jacquemier et al. ${ }^{23}$ 
One of the main questions was whether Ki-67 provides prognostic information in routine use. In former studies, Ki-67 has also been valued as a prognostic factor being associated with breast cancer outcomes.

$\mathrm{Ki}-67$ index previously has been already considered as a biomarker for therapeutic decision ${ }^{24}$. Colozza et al. ${ }^{25}$ reviewed the role of proliferation markers as prognostic and predictive tools in early breast cancer.

Two meta-analyses including studies performed between 2006 and 2011 elucidate the prognostic role of Ki-67 in breast cancer. It is notable that in both meta-analyses, the included studies applied different eligibility criteria, study design, methods for analyzing Ki-67, and cut-off points. The meta-analysis of de Azambuja et al investigated the prognostic value of Ki-67 only in univariate analyses for survival.

In this study, it was confirmed that Ki-67 is as a prognostic factor in breast cancer patients. A 2010 published review article concluded increasing evidence that Ki-67 is a valuable prognostic marker but as to its predictive role its applicability is limited ${ }^{26}$. No robust evidence was found that Ki-67 can serve as a tool to identify patients who will benefit from a specific chemotherapy or endocrine treatment. Nevertheless, the validation of Ki-67 as a predictive factor was not the subject of the present study. Because of the short duration of follow up, the survival benefits were not analyzed in this study.

This topic has been investigated in recent studies with inconsistent results. Contrary to the prognostic markers, predictive markers shall support in decision making of certain therapies as they appreciate the potential to respond to a therapy. Various studies have explored the predictive value of Ki-67-labeling index of which some of them reported an association between high-pretreatment Ki-67-labeling index and better responses to chemotherapy in the neo-adjuvant setting ${ }^{27}$ whereas other studies found no such association ${ }^{28}$.

\section{Conclusion}

In this study, the Ki-67 index had a distribution ranging from 10 to $44 \%$ and the mean value was $20 \%$ in the 128 patients studied. A higher Ki-67 index (> 20\%) correlated significantly with young age, larger tumors, positive lymphnodes. The proliferative activity as determined by Ki-67 index may reflect the aggressive behavior of breast cancer. It is therefore important to incorporate the Ki-67 index in the routine clinical settings.

\section{Acknowledgements: Nil \\ Conflicts Of Interest: Nil}

\section{References}

[1]. GLOBOCON 2012, Inter National Agency for research on cancer, IARC online database

[2]. Parkin M, Bray F, Ferlay J, Pisani P [2005] Global cancer statistics, 2002. CA Cancer J Clin. 55:74-108.

[3]. The Hallmarks of Cancer, Douglas Hanahan*et al Weinberg Department of Biochemistry and Biophysics and Hormone Research Institute University of California at San Francisco, Cell, Vol. 100, 57-70, January 7, 2000

[4]. Assessing the clinical impact of prognostic factors Hayes DF, Trock B, Harris AL Breast Cancer Res Treat. 1998;52(1-3):305.

[5]. de Azambuja E, Cardoso F, de Castro G Jr, et al . Ki-67 as prognostic marker in early breast cancer: a meta-analysis involving 12,155 patients. Br J Cancer. 2007; 96 (10): 1504 - 1513.

[6]. Ki-67 as prognostic marker in early breast cancer: a meta-analysis of published studies involving 12,155 patients de Azambuja E, Cardoso F, de Castro G Jr, M Br J Cancer. 2007;96(10):1504.

[7]. Proliferation markers and survival in early breast cancer: a systematic review and meta-analysis of 85 studies in 32,825 patients. Stuart-Harris R, Breast. 2008 Aug; 17(4):323-34. Epub 2008 May 2

[8]. An international Ki67 reproducibility study. Polley MY, Leung SC et al International Ki67 in Breast Cancer Working Group of the Breast International Group and North American Breast Cancer Group J Natl Cancer Inst. 2013;105(24):1897.

[9]. Nielsen TO, Polley M-YC, on behalf of the International Ki-67 in Breast Cancer Working Group of BIG-NABCG. An international Ki67 reproducibility study: Harmonizing scoring methodology. San Antonio Breast Cancer Symposium 2013; S2-07

[10]. American Society of Clinical Oncology 2007 update of recommendations for the use of tumor markers in breast cancer. Harris L, Fritsche H et al American Society of Clinical Oncology J Clin Oncol. 2007;25(33):5287

[11]. Molecular subclasses of breast cancer: how do we define them? The IMPAKT 2012 Working Group Statement. Guiu S, Michiels S, AndréF, Ann Oncol. 2012 Dec;23(12):2997-3006

[12]. Cuzick J, Ellis IO et al (2011) Prognostic value of ER, PR, Ki-67, and HER 2 immuno-histochemical score and comparison with recurrence score in early breast cancer. J Clin Oncol 29(32): 4273-4278.

[13]. Schmidt M, Beckmann MW, Ko“lbl H (2012) Biomarkers in Breast Cancer: An Update. Geburtsh Frauenheilk 72(9):819-832. doi:10.1055/s-0032

[14]. Elston CW, Ellis IO (1991) Pathological prognostic factors in breast cancer. I. The value of histological grade in breast cancer: experience from a large study with long-term follow-up. Histo-pathology 19:403-410

[15]. Elston CW, Ellis IO (1993) Method for grading breast cancer. J Clin Pathol 46(2):189-190

[16]. Sahin AA, Ro J, Ro JY, (1991) Ki-67 immunostaining in node-negative stage I/II Ca breast. Significant correlation with prognosis. Cancer 68(3):549-557

[17]. Rudas M, Gnant MF, Reiner G, Reiner A (1994) Thymidine labeling index and Ki-67 growth fraction in breast cancer: comparison and correlation with prognosis. Breast Cancer Res Treat 32(2): 165-175

[18]. Pinder SE, Wencyk P, Ellis IO (1995) Assessment of the new proliferation marker MIB1 in breast carcinoma using image analysis: associations with other prognostic factors and survival. Br J Cancer 71(1):146-149

[19]. Pierga JY, Leroyer A, Viehl P, (1996) Long term prognostic value of growth fraction determination by Ki-67 immunostaining in primary operable breast cancer. Breast Cancer Res Treat 37(1):57-64

[20]. Liu S, Edgerton SM, Moore DH 2nd, Thor AD (2001) Measures of cell turnover (proliferation and apoptosis) and their association with survival in breast cancer. Clin Cancer Res 7(6):1716-1723 
[21]. Kontzoglou K, Palla V, Karaolanis G, Konstantoudakis K, Stamatakos M (2013) Correlation between Ki67 and Breast Cancer Prognosis. Oncologym84(4) : 219-225. doi: 10.1159/000346475

[22]. Viale G, Ohlschlegel C et al (2008) Prognostic and predictive value of centrally reviewed Ki-67 labeling index in postmenopausal women with endocrine-responsive breast cancer: results from Breast International Group Trial 1-98 comparing adjuvant tamoxifen with letrozole. J Clin Oncol 26(34):5569-5575.

[23]. Jacquemier J, Charafe-Jauffret E, (2009) Association of GATA3, P53, Ki67 status and vascular peritu-moral invasion are strongly prognostic in luminal breast cancer. Breast Cancer Res 11(2):R23. doi:10.1186/bcr2249

[24]. Loehberg CR, Brunner M et al (2013) Prognostic relevance of Ki-67 in the primary tumor for survival after a diagnosis of distant metastasis. Breast Cancer Res Treat 138(3):899-908

[25]. Colozza M, Azambuja E, Cardoso F, Sotiriou C, Larsimont D, Piccart MJ (2005) Proliferative markers as prognostic and pre-dictive tools in early breast cancer: where are we now? Ann Oncol 16:1723-173

[26]. Yerushalmi R, Hayes MM, Gelmon KA (2010) Ki67 in breast cancer: prognostic and predictive potential. Lancet Oncol 11:174183

[27]. Chang J, Ormerod M, Powles TJ, (2000) Apoptosis and proliferation as predictors of chemotherapy response in patients with breast carcinoma. Cancer 89(11):2145-2152

[28]. Colleoni M, Zahrieh D, Goldhirsch A (2003) Preoperative systemic treatment: prediction of responsiveness. Breast 12(6):538-542 